\title{
Perbandingan Hasil Belajar Matematika Menggunakan Model Pembelajaran Means Ends Analysis (MEA) dengan Model Pembelajaran Konvensional Pokok Bahasan Dimensi Tiga
}

\author{
Asmedy \\ Program Studi Pendidikan Teknologi Informasi, STKIP Yapis Dompu \\ E-mail:asmedy.ainara@gmail.com
}

Article History: Received: 2021-01-05 || Revised: 2021-02-15 || Published: 2021-04-09

Sejarah Artikel : Diterima: 2021-01-05 || Direvisi: 2021-02-15 || Dipublikasi: 2021-04-09

\begin{abstract}
The study was conducted to determine whether there are differences and which learning outcomes are good between the learning outcomes of students being taught with the Means Ends Analysis learning model with the conventional learning model on the subject of three dimensions. This research was conducted at MAN 1 Dompu in April 2020. The research subjects were 59 students in two classes, namely class X-1 and class X-3. This study used an experimental design, namely, one learning experiment class using Means Ends Analysis learning and one control class learning using conventional learning models. The results obtained in this study are that there are differences in the pre-test results between the experimental class and the control class with the value of $\mathrm{Z}$ count $<\mathrm{Z}$ table, namely $-0.16<1.96$. From the results of the post-test, there is a difference between the experimental class and the control class with the value $-\mathrm{t}$ table $<\mathrm{tcount}>\mathrm{t}$ table, namely -1.19 $<5.41>1.19$. Not only are the results of the pre-test and post-test values calculated, but also the difference between the pre-test-post-test (gain value) shows that the gain value of the experimental class is higher than the control class with the tcount $>\mathrm{t}$ table of $3 ., 2>1.67$. Thus it can be concluded that there is a difference between student learning outcomes taught by the Means Ends Analysis learning model and student learning outcomes taught with expository strategies on the subject of three dimensions. And the learning outcomes of students who are taught with the Means Ends Analysis learning model show that it is better than the learning outcomes of students who are taught with conventional learning models.
\end{abstract}

Keywords: Means Ends Analysis, Conventional, Learning Outcomes, Three Dimention.

\begin{abstract}
Abstrak
Penelitian dilakukan bertujuan untuk mengetahui adakah perbedaan dan hasil belajar mana yang baik antara hasil belajar siswa yang diajar dengan model pembelajaran Means Ends Analysis dengan model pembelajaran Konvensional pada pokok bahasan dimensi tiga. Penelitian ini dilakukan di MAN 1 Dompu pada bulan April 2020. Subjek penelitian adalah 59 siswa di dua kelas yaitu kelas X-1 dan kelas X-3. Penelitian ini manggunakan design eksperimental yaitu, satu kelas eksperimen belajar dengan menggunakan pembelajaran Means Ends Analysis dan satu kelas kontrol belajar dengan menggunakan model pembelajaran Konvensional. Hasil yang diperoleh dalam penelitian ini adalah terdapat perbedaan hasil pre-test antara kelas eksperimen dan kelas kontrol dengan nilai Z hitung $<\mathrm{Z}$ tabel yaitu $-0,16<1.96$. Dari hasil post-testnya terdapat perbedaan antara kelas eksperimen dan kelas kontrol dengan nilai $-t_{\text {tabel }} \leq t_{\text {hitung }} \geq t_{\text {tabel }}$ yaitu $-1,19 \leq 5,41 \geq 1,19$. Tidak hanya hasil dari nilai pre-test dan post-test yang dihitung, tetapi juga hasil selisih dari nilai pre-test-post-test (nilai gain) menunjukan nilai gain kelas eksperimen lebih tinggi daripada kelas kontrol dengan nilai $t_{\text {hitung }}>\mathrm{t}_{\text {tabel }}$ yaitu $3,2>1.67$. Dengan demikian dapat disimpulkan bahwa ada perbedaan antara hasil belajar siswa yang diajar dengan model pembelajaran Means Ends Analysis dengan hasil belajar siswa yang diajar dengan strategi ekspositori pada pokok bahasan dimensi tiga. Dan hasil belajar siswa yang diajar dengan model pembelajaran Means Ends Analysis menunjukan lebih baik dari pada hasil belajar siswa yang diajar dengan model pembelajaran konvensional.
\end{abstract}

Kata kunci: Means Ends Analysis, Konvensional, Hasil Belajar, Dimensi Tiga.

\section{PENDAHULUAN}

Sekolah merupakan sarana yang secara sengaja dirancang untuk melaksanakan pendidikan. Tugas pendidikan adalah memanusiakan manusia. Manusia yang berpotensi itu dapat berkembang 
ke arah yang lebih baik, tetapi dapat pula berkembang ke arah yang tidak baik. Oleh karena itu dilakukan berbagai usaha yang disadari sepenuhnya dan dirancang secara sistematris agar perkembangan itu menuju arah yang baik. Berdasarkan pernyataan tersebut, di sekolah dalam menjalankan pendidikan tidak lepas dari yang namanya proses kegiatan belajar mengajar yang terdiri antara pendidik dan siswa. Proses belajar mengajar terjadi karena adanya interaksi yang sifatnya saling mempengaruhi demi tercapainya suatu pengajaran yang baik.

Pada hakikatnya belajar merupakan kegiatan yang tidak terpisahkan dari kehidupan manusia, secara alamiah proses belajar sudah terjadi sejak manusia terlahir. Belajar merupakan suatu kebutuhan bagi manusia untuk bertahan hidup dan mengembangkan dirinya dalam menghadapi perkembangan zaman. Pendidikan merupakan usaha manusia untuk mengembangkan kemampuannya, terutama dalam penguasaan ilmu pengetahuan dan teknologi. Pendidikan melalui proses belajar mengajar diselenggarakan di sekolah. Dalam kegitan belajar mengajar tidak lepas dari peran guru sebagai fasilitator dan motivator, karena tugas seorang guru di kelas adalah mengelola pembelajaran dan menyampaikan materi kepada siswanya. Proses belajar mengajar yang baik akan menempatkan guru sebagai pengelola pembelajaran dan bukan sebagai pemberi informasi utama, sehingga siswa akan cenderung aktif dalam memecahkan masalah-masalah yang dihadapinya.

Teknik mengajar merupakan syarat mutlak bagi guru dalam melaksanakan proses belajar mengajar, harapannya agar siswa dapat belajar secara aktif dan sesuai dengan tujuan yang ditetapkan. Banyaknya metode mengajar menuntun guru untuk selektif dalam memilih metode yang akan digunakan dalam proses belajar mengajar di kelas. Djamarah (1996:2) menyatakan bahwa metode mengajar yang akan digunakan oleh guru harus jelas dan sesuai dengan tujuan yang akan dicapai, bahan yang akan diajarkan serta jenis kegiatan belajar siswa yang diinginkan. Hal lain yang harus dilihat yaitu penggunaan metode mengajar yang digunakan oleh guru harus dapat mendorong tumbuhnya kegiatan belajar siswa secara optimal dalam bentuk kegiatan mandiri maupun kelompok. Dalam proses pembelajaran banyak ditemui siswa yang cenderung pasif, yaitu pada pembelajaran yang didominasi oleh guru dengan metode ceramah.

Dari hal-hal tersebut di atas untuk mencapai tujuan pendidikan matematika peran guru sangat penting. Dengan perkembangan jaman banyak bermunculan model-model pembelajaran yang ada di sekolah-sekolah. Dari permasalahan yang diperoleh, ada beberapa hal yang dapat digunakan dalam pemecahan masalah di atas salah satunya adalah menggunakan model pembelajaran inovatif. Dari model pembelajaran konvensional, berkembang menjadi model pembelajaran yang menarik dan tidak membosankan lagi. Tetapi masih banyak guru atau tenaga pengajar yang memakai model pembelajaran konvensional dalam kegiatan pembelajaran. Ini bisa berarti bahwa guru atau tenaga pengajar hanya bisa memakai model pembelajaran konvensional dan tidak berusaha untuk mencari model-model pembelajaran yang mungkin lebih bagus dan lebih cocok diterapkan untuk siswa-siswanya, atau bisa jadi hanya model pembelajaran konvensional yang cocok diterapkan untuk siswa-siwanya.

Model pembelajaran konvensional yaitu model pembelajaran yang menekankan cara penyampaian pembelajaran dimana guru lebih aktif di depan dan siswa-siswanya hanya memperhatikan dan cenderung pasif. Pembelajaran pada model konvensional lebih berpusat pada guru sehingga tidak memberi kesempatan siswa untuk berpikir logis, kritis, dan kreatif, serta kemampuan bekerjasama. Berdasarkan penjelasan di atas, maka model pembelajaran konvensional dapat dimaknai sebagai model pembelajaran yang lebih banyak berpusat pada guru, komunikasi lebih banyak satu arah dari guru ke siswa, metode pembelajaran lebih banyak menggunakan ceramah dan demonstrasi, dan materi pembelajaran lebih pada penguasaan konsep-konsep bukan kompetensi. 
Pembelajaran inovatif lebih memberikan peluang kepada siswa untuk mengkonstruksi pengetahuannya secara mandiri dan memotivasi siswa untuk aktif dan kreatif dalam pembelajaran. Salah satu model pembelajaran inovatif yang dapat digunakan adalah model pembelajaran MeansEnds Analysis (MEA). Model pembelajaran Means-Ends Analysis (MEA) yaitu memecahkan suatu masalah ke dalam dua atau lebih subtujuan dan materi pendekatan pemecahan masalah berbasis heuristik. Heuristik dalam matematika adalah suatu langkah umum yang memandu pemecah masalah dalam menemukan solusi masalah.

Model pembelajaran Means Ends Analysis menghendaki seorang pemecah masalah untuk menentukan tujuan (ends) dari suatu masalah yang hendak dicapai dan cara (means) yang dapat membantunya untuk mencapai tujuan tersebut. Proses awal yang dilakukan pada Means Ends Analysis adalah memahami suatu masalah yang meliputi proses pendeteksian current state (pernyataan sekarang) dan goal state (tujuan). Setelah dilakukan pendekatan dan mencatat current state dan goal state perlu dicari perbedaan diantara kedua hal tersebut. Kemudian dilakukan pereduksian perbedaan tersebut. Keadaan ini perlu disesuaikan dengan kebutuhan agar suatu submasalah menjadi suatu keadaan yang nantinya dapat teraplikasikan pada masalah yang ada. Selanjutnya gunakan perbedaan antara current state dan goal state untuk menyeleksi prosedur yang akan digunakan. Berdasarkan uraian di atas, perlu kiranya diteliti dengan menggunakan metode pembelajaran yang baru, yaitu pembelajaran dengan model pembelajaran Means Ends Analysis, yang diharapkan metode ini lebih baik dari pada model pembelajaran konvensional, disamping itu diharapakan siswa mencapai KKM yang ditetapkan oleh sekolah dan tercipta hasil pembelajaran yang lebih baik. Karena itu peneliti tertarik untuk melakukan penelitian tentang "Perbandingan Hasil Belajar Matematika Siswa MAN 1 Dompu Menggunakan Model Pembelajaran Means Ends Analysis Dengan Model Pembelajaran Konvensional"

\section{METODE PENELITIAN}

Penelitian ini termasuk jenis penelitian eksperimental. "Dalam penelitian eksperimen ada perlakuan (treatment), sedangkan dalam penelitian naturalistik tidak ada perlakuan. Dengan demikian metode penelitian eksperimen dapat diartikan sebagai metode penelitian yang digunakan untuk mencari pengaruh perlakuan tertentu terhadap yang lain dalam kondisi yang dikendalikan" (Sugiyono, 2013:107). Jadi dalam penelitian eksperimental terdapat perbedaan antara penelitian yang mendapatkan perlakuan dengan yang tidak mendapatkan perlakuan. Dalam penelitian eksperimental terdapat dua variabel yaitu variabel bebas atau perlakuan dan variabel kontrol. Variabel bebas atau perlakuan dalam penelitian ini adalah pembelajaran dengan menggunakan model pembelajaran Means Ends Analysis, sedangkan variabel kontrol dalam penelitian ini adalah pembelajaran dengan menggunakan model pembelajaran konvensional, jenis dan pendekatan penelitian di atas, dalam penelitian ini menggunakan dua kelas yaitu kelas eksperimen dan kelas kontrol dengan mengunakan desain penelitian "Pretest-Posttest Control Group Design" (Sugiyono, 2013:112). Penelitian ini dilaksanakan di dua kelas, yaitu kelas kontrol dan kelas eksperimen. Pada kelas eksperimen diberikan treatment atau pembelajaran dengan menggunakan model pembelajaran Means Ends Analysis, sedangkan kelas kontrol menggunakan model pembelajaran konvensional. Sebelum kedua kelas diberikan perlakuan, terlebih dahulu diberikan tes awal $\left(\mathrm{O}_{1}, \mathrm{O}_{3}\right)$. Kemudian kedua kelas diberi perlakuan (X), dan setelah itu diberikan tes akhir $\left(\mathrm{O}_{2}, \mathrm{O}_{4}\right)$ untuk melihat adanya perbedaan hasil belajar atau tidak. Adapun secara garis besar dapat dilukiskan pada bagan arus penelitian yang akan dilakukan adalah sebagai berikut: 


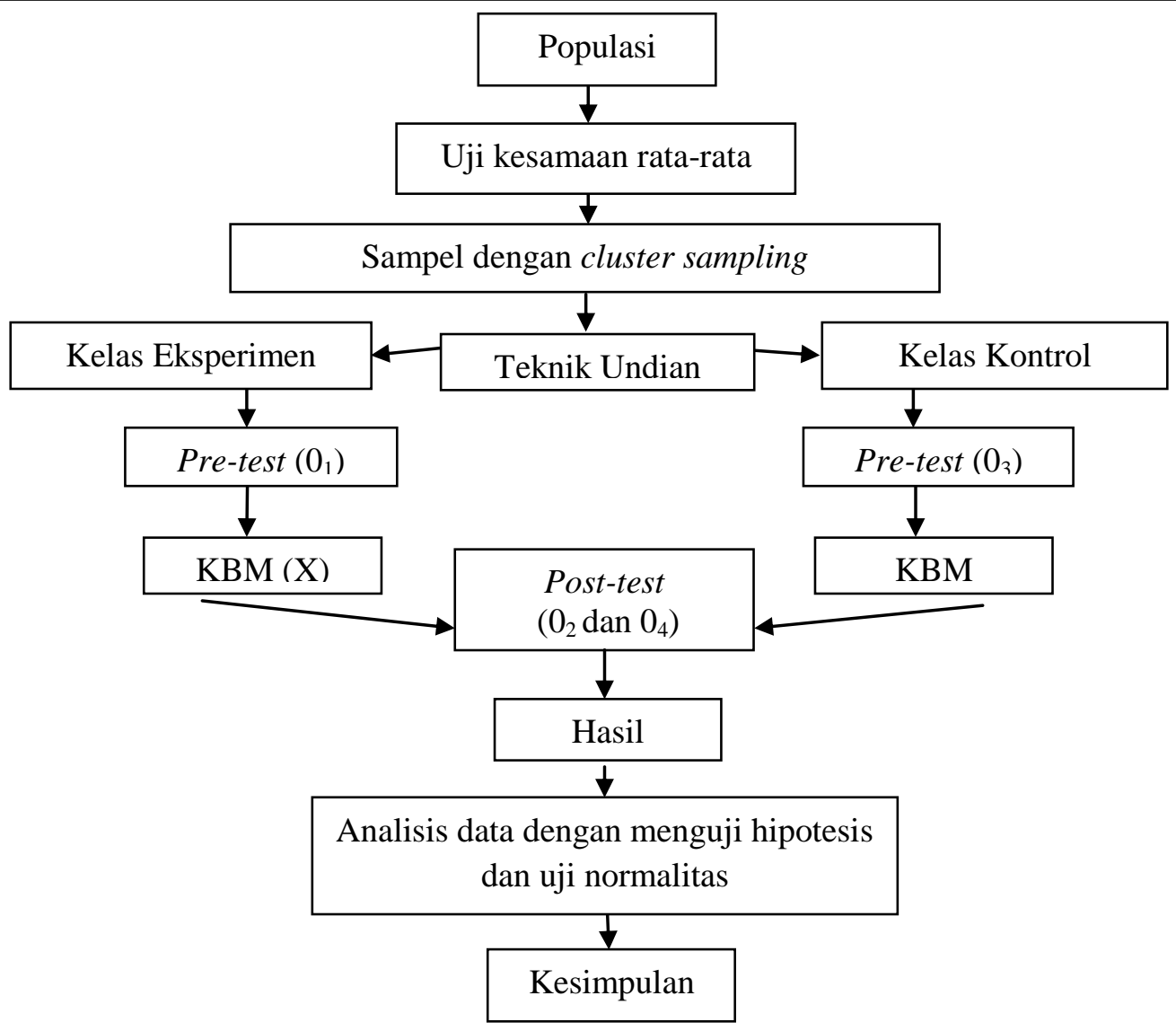

Gambar 1. Alur dalam Penelitian

\section{HASIL DAN PEMBAHASAN}

\section{Hasil Pre-Test}

Pre-test dilakukan untuk mengetahui sejauh mana pemahaman awal siswa baik pada kelas eksperimen maupun kelas kontrol. Adapun nilai yang terendah pada kelas eksperimen adalah 6 dan nilai tertingginya adalah 44 kemudian untuk kelas kontrol nilai terendah adalah 3 dan nilai tertingginya adalah 44 . Untuk lebih jelasnya dapat dilihat pada tabel berikut:

Tabel 1. Perbandingan Nilai Pre-Test Siswa Kelas Eksperimen dan Kelas Kontrol

\begin{tabular}{clcc}
\hline No & Komponen & Kelas Eksperimen X-1 & Kelas Kontrol X-3 \\
\hline 1 & Jumlah Siswa & 29 & 30 \\
\hline 2 & Nilai Terendah & 6 & 44 \\
\hline 3 & Nilai Tertinggi & 3 & 44 \\
\hline 4 & Nilai Rata - Rata & 27,1 & 26,3 \\
\hline 5 & Varians & 138,99 & 119,39 \\
\hline 6 & Standard Deviasi & 11,29 & 11,35 \\
\hline
\end{tabular}

\section{Uji Normalitas}

Uji Normalitas dilakukan menggunakan rumus Chi-Kuadrat (团国) baik pada nilai pre-test maupun pada nilai post-test. Dikatakan berdistribusi normal nantinya jika 国目hitung < 国国tabel .

Tabel 2. Uji Normalitas Pre-Test Kelas Eksperimen dan Kelas Kontrol

\begin{tabular}{ccccccc}
\hline No & Kelas & N & $\alpha$ & t-hitung & t-tabel & Distribusi \\
\hline 1 & Kelas X-1 (Eksperimen) & 29 & 0,05 & 19,4978 & 7,81 & Tidak Normal \\
\hline 2 & Kelas X-3 (Kontrol) & 30 & 0,05 & 16,387 & 7,81 & Tidak Normal \\
\hline
\end{tabular}

Berdasarkan keterangan pada tabel uji normalitas nilai pre-test kelas eksperimen dan kelas kontrol, dapat disimpulkan bahwa kelas eksperimen tidak berdistribusi normal sedangkan kelas kontrol hasilnya juga sama seperti kelas eksperimen yaitu tidak berdistribusi normal. 
Uji Mann Whitney dari Hasil Pre - Test (Uji Dua Pihak)

Pengujian yang sesuai dengan data pre-test baik kelas eksperimen maupun kelas kontrol yaitu dengan teknik Mann-Whitney Tes karena data yang digunakan tidak berdistribusi normal tetapi homogen. Teknik Mann-Whitney Tes (uji-U) untuk sampel besar, menggunakan harga kririk Z. Adapun hipotesis dan tabel Zhitung hasil pre-test adalah sebagai berikut:

a) Perumusan Hipotesis dalam kalimat

Ho : Tidak ada perbedaan antara hasil pre-test dari kelas eksperimen dengan kelas kontrol

Ha : Ada perbedaan antara hasil pre-test dari kelas eksperimen dengan kelas kontrol

b) Kriteria Pengujian

Dengan uji dua pihak dan mengambil taraf signifikan $=5 \%=0.05$, dan Ho diterima jika $-\mathrm{Z}$ $1 / 2(1-\alpha)<Z$ hitung $<Z^{1 / 2}(1-\alpha)$. Sehingga $Z^{1 / 2}(1-\alpha)=Z^{1 / 2}(1-0.05)=1.96$. dan apabila nilai $\mathrm{Z}$ hitung jatuh pada daerah penolakan Ho, maka Ha diterima, begitu juga sebaliknya.

Tabel 3. Data Hasil Pre-Test dengan Uji Mann Whitney

\begin{tabular}{lcc}
\hline & Kelas Eksperimen X-1 & Kelas Kontrol X-3 \\
\hline Jumlah Sampel (n) & 29 & 30 \\
\hline Jumlah Ranking & 866,5 & 923,5 \\
\hline z hitung & & $-0,16$ \\
z tabel & \multicolumn{3}{r}{} \\
\hline
\end{tabular}

\section{Kesimpulan}

Berdasarkan hasil penelitian, diperoleh keterangan yang menyatakan bahwa nilai dari Z hitung jatuh pada penolakan Ho, maka itu artinya ada perbedaan antara hasil pre-test siswa pada kelas eksperimen dengan hasil belajar siswa pada kelas kontrol. Sehingga dapat dikatakan bahwa antara siswa kelas eksperimen dengan kelas kontrol memiliki kemampuan awal yang sama.

\section{Hasil Post-Test}

Post-test dilakukan untuk mengetahui tingkat pemahaman siswa setelah pelaksanaan pembelajaran baik pada kelas eksperimen maupun kelas kontrol. Adapun nilai yang terendah pada kelas eksperimen adalah 70 dan tertingginya adalah 95 kemudian untuk kelas kontrol nilai terendah adalah 52 dan tertingginya adalah 91. Jika dibandingkan antara kedua kelas tersebut kelas eksperimen lebih unggul daripada kelas kontrol. Untuk lebih jelasnya dapat dilihat pada tabel berikut:

Tabel 4 Perbandingan Nilai Post-Test Siswa Kelas Eksperimen dan Kelas Kontrol

\begin{tabular}{clcc}
\hline No & Komponen & Kelas Eksperimen X-1 & Kelas Kontrol X-3 \\
\hline 1 & Jumlah Siswa & 29 & 30 \\
\hline 2 & Nilai Terendah & 70 & 52 \\
\hline 3 & Nilai Tertinggi & 95 & 91 \\
\hline 4 & Nilai Rata - Rata & 82 & 71 \\
\hline 5 & Varians & 41,9 & 65,7 \\
\hline 6 & Standard Deviasi & 6,5 & 8,9 \\
\hline
\end{tabular}

\section{Uji Normalitas}

Tabel 5. Uji Normalitas Post -Test Kelas Eksperimen dan Kelas Kontrol

\begin{tabular}{|c|c|c|c|c|c|c|}
\hline No & Kelas & $\mathrm{N}$ & $\alpha$ & 国国hitung & ? 目 tabel & Distribusi \\
\hline 1 & Kelas X-1 (Eksperimen) & 29 & 0,05 & 5,4751 & 7,81 & Normal \\
\hline 2 & Kelas X-3 (Kontrol) & 30 & 0,05 & 0,5064 & 7,81 & Normal \\
\hline
\end{tabular}

Berdasarkan tabel di atas dapat diketahui bahwa nilai hitung pada kelaseksprimen kurang dari tabel, sehingga dapat disimpulkan bahwa kelas ekperimen berdistribusi normal. Sedangkan pada kelas kontrol diketahui nilai hitung kurang dari tabel, sehingga diperoleh kesimpulan bahwa kelas kontrol juga berdistribusi normal. 
Uji Homogenitas Varians

Analisis homogenitas data bertujuan untuk mengetahui homogen tidaknya varians sampelsampel penelitian yang diambil dari populasi yang sama. Hasil uji homogenitas nilai post-test antara kelas eksperimen dan kelas kontrol ditunjukkan pada tabel berikut:

Tabel 6. Uji Homogenitas Post-Test Kelas Eksperimen dan Kelas Kontrol

\begin{tabular}{|c|c|c|c|c|c|c|c|}
\hline Kelas & Jumlah & $\begin{array}{l}\text { Rata - Rata } \\
\text { (Mean) }\end{array}$ & Varians & $\begin{array}{l}\text { Standar } \\
\text { Deviasi (sd) }\end{array}$ & $\begin{array}{l}\mathrm{F} \\
\text { Hitung }\end{array}$ & $\begin{array}{l}\mathrm{F} \\
\text { Tabel }\end{array}$ & Keterangan \\
\hline$X-1$ & 29 & 82 & 41,9 & 6,5 & & & \\
\hline $\begin{array}{c}X- \\
3\end{array}$ & 30 & 71 & 65,7 & 8,9 & 1,57 & 2,12 & Homogen \\
\hline
\end{tabular}

Berdasarkan data tabel di atas, diketahui bahwa kelas eksperimen dan kelas kontrol pada nilai post-test memiliki varians sama atau homogen. Hal ini ditunjukkan dari nilai Fhitung yaitu 1.57 $<$ nilai Ftabel yaitu 2,12.

\section{Hasil Gain}

Nilai gain diperoleh berdasarkan hasil perhitungan nilai post-tes dikurangi dengan nilai pre-test. Perhitungan gain dilakukan untuk melihat perubahan dari nilai pre-test kenilai post-test nya, ada bedanya atau tidak. Yang dimaksud beda disini untuk melihat selisih hasil belajar manakah yang lebih tinggi antara kelas eksperimen dan kelas kontrol. Untuk lebih jelasnya adapun tabel nilai hasil gain adalah sebagai berikut:

Tabel 7. Perbandingan Nlai Gain Siswa Kelas Eksperimen dan Kelas Kontrol

\begin{tabular}{llll}
\hline No & Komponen & Kelas Eksperimen X-1 & Kelas Kontrol X-3 \\
\hline 1 & Jumlah Siswa & 29 & 30 \\
\hline 2 & Nilai Terendah & 33 & 22 \\
\hline 3 & Nilai Tertinggi & 85 & 81 \\
\hline 4 & Nilai Rata - Rata & 59,3 & 47,2 \\
\hline 5 & Varians & 172,1 & 232,3 \\
\hline 6 & Standard Deviasi & 13,1 & 15,2 \\
\hline
\end{tabular}

\section{Uji Normalitas}

Tabel 8. Uji Normalitas Gain Kelas Eksperimen dan Kelas Kontrol

\begin{tabular}{|c|c|c|c|c|c|c|}
\hline No & Kelas & $\mathrm{N}$ & $\alpha$ & 目目固hitung & ? 目目tabel & Distribusi \\
\hline 1 & Kelas X-1 (Eksperimen) & 29 & 0,05 & 1,5406 & 7,81 & Normal \\
\hline 2 & Kelas X-3 (Kontrol) & 30 & 0,05 & 3,1920 & 7,81 & Normal \\
\hline
\end{tabular}

Berdasarkan tabel di atas dapat diketahui bahwa nilai hitung pada kelaseksprimen kurang dari tabel, sehingga dapat disimpulkan bahwa kelas ekperimen berdistribusi normal. Sedangkan pada kelas kontrol diketahui nilai hitung kurang dari tabel, sehingga diperoleh kesimpulan bahwa kelas kontrol juga berdistribusi normal.

\section{Uji Homogenitas}

Analisis homogenitas data bertujuan untuk mengetahui homogen tidaknya varians sampelsampel penelitian yang diambil dari populasi yang sama. Hasil uji homogenitas nilai gain antara kelas eksperimen dan kelas kontrol ditunjukkan pada tabel berikut:

Tabel 9. Uji Homogenitas Nilai Gain Kelas Eksperimen dan Kelas Kontrol

\begin{tabular}{llllllll}
\hline Kelas & Jumlah & Rata - Rata (Mean) & Varians & $\begin{array}{l}\text { Standar } \\
\text { Deviasi (sd) }\end{array}$ & $\begin{array}{l}\text { F } \\
\text { Hitung }\end{array}$ & $\begin{array}{l}\mathrm{F} \\
\text { Tabel }\end{array}$ & \multirow{2}{*}{ Keterangan } \\
\hline $\mathrm{X}-1$ & 29 & 59,3 & 172,1 & 13,1 & 1,35 & 2,12 & \multirow{2}{*}{ Homogen } \\
\hline $\mathrm{X}-3$ & 30 & 47,2 & 232,3 & 15,2 & & & \\
\hline
\end{tabular}


Berdasarkan data tabel di atas, diketahui bahwa kelas eksperimen dan kelas kontrol pada nilai post-test memiliki varians sama atau homogen. Hal ini ditunjukkan dari nilai Fhitung yaitu $1.35<$ nilai Ftabel yaitu 2,12.

\section{Uji Hipotesis Penelitian}

Untuk Mengetahui Adanya Perbedaan Hasil Belajar Siswa yang diajar dengan Menggunakan Model Pembelajaran Aktif Means Ends Analysis dengan Model Pembelajaran Konvensional, Pengujian yang sesuai dengan data post-test baik kelas eksperimen maupun kelas kontrol yaitu dengan analisis uji t karena data yang digunakan berdistribusi normal dan homogen.

Adapun hipotesis hasil post-test adalah sebagai berikut:

a) Perumusan Hipotesis dalam kalimat

Ho : Tidak ada perbedaan antara hasil belajar dari kelas eksperimen dengan kelas kontrol

$\mathrm{Ha}$ : Ada perbedaan antara hasil belajar dari kelas eksperimen dengan kelas kontrol

b) Kriteria Pengujian

Dengan uji dua pihak dan mengambil taraf signifikan $=5 \%=0.05$, dan Ha diterima jika $-t_{\text {tabel }} \leq$ $t_{\text {hitung }} \geq t_{\text {tabel }}$. Apabila nilai $t$ jatuh pada daerah penolakan Ho, maka Ha diterima, begitu juga sebaliknya.

Tabel 10. Uji t (dua pihak) Nilai Post-test Kelas Eksperimen dan Kelas Kontrol

\begin{tabular}{lll}
\hline & Kelas Eksperimen X-1 & Kelas Kontrol X-3 \\
\hline Jumlah Siswa & 29 & 30 \\
\hline Nilai Rata - Rata & 82 & 71 \\
\hline$\Sigma_{\text {x2 }}$ & 1173 & 2296 \\
\hline$\Sigma_{y 2}$ & 82 & 71 \\
\hline Db & 57 & \\
\hline thitung & 5,41 & \\
\hline ttabel & 1,19 & \\
\hline
\end{tabular}

Berdasarkan hasil penelitian, diperoleh keterangan yang menyatakan bahwa nilai dari t jatuh pada penolakan Ho, maka itu artinya terdapat perbedaan antara hasil belajar siswa pada kelas eksperimen (siswa yang diajar dengan model pembelajaran Means Ends Analyisis) dengan hasil belajar siswa pada kelas kontrol (siswa yang diajar dengan Model Pembelajaran Konvensional).

Untuk Mengetahui Hasil Belajar Siswa yang Diajar dengan Menggunakan Model Pembelajaran Means Ends Analysis (MEA) Lebih Baik dari pada Hasil Belajar Siswa dengan Model Pembelajaran Konvensional Pengujian yang sesuai dengan data post-test baik kelas eksperimen maupun kelas kontrol yaitu dengan analisis uji t karena data yang digunakan berdistribusi normal dan homogen. Adapun hipotesis hasil post-test adalah sebagai berikut:

a) Perumusan Hipotesis dalam kalimat

Ho : Hasil belajar siswa kelas eksperimen tidak lebih baik atau sama dengan hasil belajar siswa kelas kontrol

Ha : Hasil belajar siswa kelas eksperimen lebih baik daripada hasil belajar siswa kelas kontrol

b) Kriteria Pengujian

Dengan uji satu pihak dan mengambil taraf signifikan $=5 \%=0.05$, dan Ha diterima jika $t_{\text {hitung }}>$ $t_{\text {tabel }}$. Apabila nilai $t$ jatuh pada daerah penolakan Ho, maka Ha diterima, begitu juga sebaliknya.

Tabel 11. Uji t Nilai (satu pihak) Post-test Kelas Eksperimen dan Kelas Kontrol

\begin{tabular}{lll}
\hline & Kelas Eksperimen X-1 & Kelas Kontrol X-3 \\
\hline Jumlah Siswa & 29 & 30 \\
\hline Nilai Rata - Rata & 82 & 71 \\
\hline$\Sigma_{\mathrm{x} 2}$ & 1173 & 2296 \\
\hline$\Sigma_{\mathrm{y} 2}$ & 82 & 71 \\
\hline Db & 57 & \\
\hline
\end{tabular}




\begin{tabular}{ll}
\hline thitung & 5,41 \\
\hline ttabel & 1,67 \\
\hline
\end{tabular}

Berdasarkan hasil penelitian, diperoleh keterangan yang menyatakan bahwa nilai dari t jatuh pada penolakan Ho, maka itu artinya hasil belajar siswa pada kelas eksperimen (siswa yang diajar dengan model pembelajaran Means Ends Analysis) lebih baik daripada hasil belajar siswa pada kelas kontrol (siswa yang diajar dengan model pembelajaran Konvensional).

\section{SIMPULAN DAN SARAN}

\section{A. Simpulan}

Berdasarkan hasil pembahasan, dapat diambil beberapa kesimpulan sebagai berikut:

1. Adanya perbedaan antara hasil belajar siswa yang diajar dengan model pembelajaran Means Ends Analysis dengan hasil belajar siswa yang diajar dengan metode pembelajaran Konvensional dengan nilai $-t_{\text {tabel }} \leq t_{\text {hitung }} \leq t_{\text {tabel }}$ dengan taraf signifikasi $5 \%$, yaitu $-1,19 \leq 5,41 \leq 1,19$.

2. Hasil belajar siswa yang diajar dengan model pembelajaran Means Ends Analysis lebih baik daripada hasil belajar siswa yang diajar dengan metode pembelajaran Konvensional dengan nilai $t_{\text {hitung }}>t_{\text {tabel }}$ dengan taraf signifikasi $5 \%$, yaitu 5,41 > 1,67.

\section{B. Saran}

Berdasarkan hasil pembahasan dan kesimpulan, dapat diberikan saran sebagai berikut:

1. Bagi guru, apabila guru mengajar menggunakan model pembelajaran Means Ends Analysis, sebaiknya:

2. Guru menyajikan materi secara kontekstual namun pengerjaan tugas tetap secara individu agar suasana kelas tetap kondusif dan guru lebih mudah untuk mengkondisikan siswa.

3. Guru memberikan kesempatan pada siswa untuk membangun kreativitasnya selama proses pembelajaran.

4. Bagi peneliti, hendaknya dapat mengembangkan penelitian yang sejenis dengan materi yang berbeda atau membandingkan model pembelajaran Means Ends Analysis dengan model atau strategi pembelajaran yang lain.

\section{DAFTAR RUJUKAN}

Arifin, Z. 2011. Penelitian Pendidikan Metode dan Paradigma Baru. Bandung: ROSDA KARYA.

Arikunto, S. (2009). Prosedur Penelitian Suatu Pendekatan Praktik. Edisi Revisi 6. Jakarta : Rineka Cipta.

Eka Yulianti, \& Taufik. (2020). Studi Perbandingan Eksistensi Alam Pada Novel Tanah Baru Tanah Air Kedua Karya Nh. Dini Dan Sri Rinjani Karya Eva Nourma (Tinjauan Ekologi Sastra). Ainara Journal (Jurnal Penelitian Dan PKM Bidang Ilmu Pendidikan), 1(2), 44-55. https://doi.org/10.1234567/ainarajournal.v1i2.13

Fathirma'ruf, \& Muhammad Akbar. (2018). Perancangan Sistem Seleksi Penerimaan Calon Mahasiswa Baru Berbasis Website. JIIP - Jurnal Ilmiah Ilmu Pendidikan, 1(3), 102-106. Retrieved from http://jiip.stkipyapisdompu.ac.id/jiip/index.php/JIIP/article/view/28

Hariyanto. 2010. Modul Metodologi Penelitian Pendidikan.

Huda,Miftahul. 2013. Model-model pengajaran dan pembelajaran.Yogyakarta : PUSTAKA PELAJAR

Hudojo, H. 1990. Pengembangan Kurikulum Dan Pembelajaran Matematika. Malang: Universitas Negeri Malang.

Riduwan dan Sunarto. 2013. Pengantar Statistika. Bandung : ALFABETA

Ruseffendi. 1998. Dasar-Dasar Penelitian Pendidikan Dan Bidang Non-Eksakta Lainnya. Semarang: IKIP Semarang. 
Sanjaya, Wina. 2013. Penelitian Pendidikan. Bandung: Kencana.

Soepeno, Bambang. 2002.Statistik Terapan.Jakarta : Rineka Cipta

Sugiyono. 2012. Metode Penelitian Kuantitatif dan Kualitatif dan R\&D. Bandung: Alfabeta.

Sugiyono. 2013. Statistika Untuk Penelitian. Bandung: ALFABETA.

Sukiman.2012.Pengembangan Sistem Evaluasi.Yogjakarta: Insan Mandiri 